\title{
MITOLOGIAS JURÍDICAS DO ESTADO ADMINISTRATIVO: CRÍTICA GENEALÓGICA DA NOÇÃO DE INTERESSE PÚBLICO
}

\author{
LEGAL MITHOLOGIES OF THE ADMINISTRATIVE STATE: \\ GENEALOGICAL CRITIQUE OF THE CONCEPT OF PUBLIC INTEREST
}

\author{
MITOLOGÍAS JURÍDICAS DEL ESTADO ADMINISTRATIVO: \\ CRÍTICA GENEALÓGICA DE LA NOCIÓN DE INTERÉS PÚBLICO
}

\author{
LiVIA Solana Pfuetzenreiter de Lima TeiXeIRA \\ https://orcid.org/0000-0003-3936-8745 / http://lattes.cnpq.br/7644151317318672 / liviasolana@gmail.com \\ Universidade Regional de Blumenau - FURB \\ Blumenau, SC, Brasil. \\ Centro Universitário Internacional - UNINTER \\ Curitiba, PR, Brasil.
}

WALTER GUANDALINI JUNIOR

https://orcid.org/0000-0003-2426-3326 / http://lattes.cnpq.br/1235236220070863 / prof.walter.g@gmail.com Universidade Federal do Paraná - UFPR / Centro Universitário Internacional - UNINTER. Curitiba, PR, Brasil.

\begin{abstract}
RESUMO
O estudo pretende realizar uma crítica genealógica do principal mito fundador do moderno Estado Administrativo: a noção de "interesse público". Partindo do método arqueogenealógico proposto por Michel Foucault, leva em consideração o desenvolvimento histórico do conceito de interesse público para demonstrar que, longe de limitar juridicamente a ação de governo de um Estado Absoluto até então incontrolável, é a própria noção de interesse público a justificar a construção teórica e política de um Estado capaz de "fazer coisas", legitimando tautologicamente, em nome do bem comum, a sua ação de governo sobre os corpos de indivíduos e populações.
\end{abstract}

Palavras-chave: biopolítica; discurso; interesse público; relações de poder; sociedade disciplinar.

\section{ABSTRACT}

This article carries out a genealogical critique of the Administrative State's main founding myth: the concept of "public interest". Considering Michel Foucault's archeogenealogical method, it takes into account the historical development of the concept of public interest to demonstrate that, instead of providing a legal limitation of an uncontrollable Absolute State's governmental action, it's this very notion that justifies the theoretical and political building of a state capable of "doing things", tautologically legitimating, in the name of the common good, its ruling over individuals' and populations' bodies.

Keywords: biopolitics; discourse; public interest; power relations; disciplinary society.

\section{RESUMEN}

El presente estudio pretende realizar una crítica genealógica del principal mito fundador del moderno Estado Administrativo: la noción de "interés público". A partir del método arqueogenalógico propuesto por Michel Foucault, tiene en cuenta el desarrollo histórico del concepto de interés público para demostrar que, lejos de limitar jurídicamente la acción de gobierno de un Estado Absoluto hasta entonces incontrolable, es la propia noción de interés público a justificar la construcción teórica y política de un Estado capaz de "hacer cosas", legitimando tautológicamente, en nombre del bien común, su acción de gobierno sobre los cuerpos de individuos y poblaciones.

Palabras clave: biopolítica; discurso; interés público; relaciones de poder; sociedad disciplinaria. 


\section{SUMÁRIO}

INTRODUÇAO; 1 A CONSTRUÇÃO DO INTERESSE PÚBLICO NA SOCIEDADE DISCIPLINAR E A INDETERMINAÇÃO DO INTERESSE PÚBLICO NA SOCIEDADE BIOPOLÍTICA; CONCLUSÃO; REFERÊNCIAS.

\section{INTRODUÇÃO}

É lugar comum na doutrina juspublicista a ideia de que uma das funções supremas do Estado é a ordenação da vida dos homens em sociedade, na incessante busca pelo resguardo do interesse público. O sentido teleológico atribuído a toda atuação estatal orienta também a construção jurídica de sua estrutura administrativa, apoiada solidamente sobre a coluna fundamental da supremacia do interesse público, a sustentar e dirigir o conjunto de intervenções de governo realizadas sobre a esfera privada dos indivíduos.

A importância atribuída à noção de interesse público para a construção do Estado Administrativo e do arcabouço jurídico que o organiza é facilmente percebida na literatura sobre o tema: é consensual entre os administrativistas a ideia de que toda ação estatal deve ser voltada à realização do interesse público. É o que afirma José dos Santos Carvalho Filho ${ }^{1}$, para quem as atividades administrativas desenvolvidas pelo Estado devem ser sempre realizadas em benefício da coletividade, mesmo quando praticadas com um fim estatal imediato; da mesma forma, Hely Lopes Meirelles aponta a primazia do interesse público sobre o privado como elemento inerente à atuação estatal, dominando-a ao justificar a própria existência do Estado, o que o torna princípio indisponível'; Maria Sylvia Zanella di Pietro considera a supremacia do interesse público como base de todas as funções do Estado e ramos do direito público³; para Odete Medauar o interesse público se refere ao bem de toda a coletividade, sendo vedado à autoridade administrativa deixar de tomar providências relevantes ao seu atendimento ${ }^{4}$; mas foi Celso Antônio Bandeira de Mello o administrativista que mais precisamente teorizou o conceito de interesse público no Brasil, ao afirmar ser ele "resultante dos interesses que os indivíduos

\footnotetext{
${ }^{1}$ CARVALHO FILHO, José dos Santos. Manual de Direito Administrativo. 28. ed. rev., ampl. e atual. São Paulo: Atlas, 2015, p. 34.

${ }^{2}$ MEIRELLES, Hely Lopes. Direito Administrativo Brasileiro. 42. ed. São Paulo: Malheiros, 2016, p. 113.

${ }^{3}$ DI PIETRO, Maria Sylvia Zanella. Direito Administrativo. 27 ed. São Paulo: Atlas, 2014, p. 37.

${ }^{4}$ MEDAUAR, Odete. Direito Administrativo Moderno. 8. ed. rev. e atual. São Paulo: Revista dos Tribunais, 2004, p. 151-152.
} 
pessoalmente têm quando considerados em sua qualidade de membros da Sociedade, e pelo simples fato de o serem" 5 .

A tese do interesse público como causa final de toda atuação estatal faz com que a própria construção jurídico-dogmática da Teoria do Estado contemporânea seja obrigada a incluir, em seu conceito de Estado moderno, para além do conjunto de elementos estruturais que o compõem (soberania, território e povo), também a articulação desse conjunto de elementos em torno de uma finalidade essencial: a promoção do interesse público, pela realização das condições necessárias à busca da felicidade e satisfação dos indivíduos que se localizam em determinado território ${ }^{6}$. Nessa perspectiva teleológica o Estado se apresenta como "facilitador" da felicidade de seus integrantes ${ }^{7}$, o que faz com que as suas intervenções regulatórias e executivas não sejam percebidas como arbitrárias e coativas, mas como estrito cumprimento de sua finalidade essencial em nome do bem comum.

Esse raciocínio teleológico acaba se apresentando em uma estrutura tautológica, na medida em que os efeitos predefinidos como resultado inevitável de toda ação estatal são tomados também como justificativa legitimadora de própria ação. Ele dá origem, assim, a um argumento cinicamente circular, no interior do qual é sempre o próprio Estado a definir o interesse público que simultaneamente legitima a priori, como causa eficiente, e valida $a$ posteriori, como causa final, as suas ações interventivas sobre a sociedade.

A única forma encontrada por esse raciocínio para romper com a circularidade argumentativa e afastar-se do pensamento mágico, consiste em buscar no mundo empírico a distinção científica apta a materializar a fantasmagoria apresentada. Pelo esforço de demonstração histórica de que foi a construção do critério do interesse público a responsável, per se, pela legitimação do agir estatal, na medida em que permitiu o rompimento democrático com o despotismo injusto e arbitrário do Estado Absolutista.

O problema é que a busca da evidência histórica é contaminada pelo interesse anacrônico de legitimação das soluções jurídicas contemporâneas, que acaba conduzindo a uma mitificação da gênese histórica do conceito de interesse público. Isso ocorre porque a narrativa constrói o seu argumento supostamente empírico sobre os alicerces fragilíssimos de uma estrutura histórica linear-positivista, organizada em uma cronologia de eventos interligados em

\footnotetext{
${ }^{5}$ MELLO, Celso Antônio Bandeira de. Curso de Direito Administrativo. 27. ed. rev, e atual. São Paulo: Malheiros, 2010, p. 61.

${ }^{6}$ DALLARI, Dalmo de Abreu. Elementos de Teoria Geral do Estado. 2016. 33. ed. São Paulo: Saraiva, 2016, p. 106.

${ }^{7}$ MELLO, Celso Antônio Bandeira de. Curso de Direito Administrativo. 27. ed. rev. e atual. São Paulo: Malheiros, 2010, p. 61.
} 
cadeia sempre ascendente, a indicar a evolução contínua do Estado Administrativo até o ápice coincidente com o modelo contemporâneo de organização estatal.

No desenrolar dessa narrativa histórica, instrumentalizada pela dogmática jurídica, o evento definido como momento crucial de constituição do direito administrativo é a formação do Estado de Direito: este verdadeiro ato fundador da nossa modernidade jurídica é concebido como resultado das lutas burguesas contra o absolutismo monárquico, que teriam finalmente permitido a afirmação de valores fundamentais da pessoa humana, passando a exigir que o aparato estatal se organizasse em torno $\operatorname{deles}^{8}$. Assim, segundo a narrativa tradicional o direito administrativo nasce da subordinação do poder à lei, da vitória da liberdade do povo sobre o despotismo do Estado - o que equivale a dizer que pelo direito administrativo o poder aceita se submeter ao direito dos cidadãos, fonte que irriga o mito de sua origem milagrosa e heroica 9

O resultado dessa construção é mais uma das tantas "certezas axiomáticas lentamente sedimentadas no intelecto e no coração dos juristas modernos" a que se refere Paolo Grossi ${ }^{10}$ : mais uma mitificação aceita de modo submisso e sem questionamento, em um processo de absolutização de noções e princípios que compelem o deslocamento do saber jurídico de um mecanismo de conhecimento para um mecanismo de crença, no caso em discussão, a contemporânea crença semirreligiosa na transcendentalidade do conceito fundamental de interesse público.

Veja-se, por exemplo, que já nas páginas iniciais do seu manual de Direito Administrativo Di Pietro ensina que a formação do Direito Administrativo encontra suas origens nas revoluções que acabaram com o velho regime absolutista, constituindo disciplina própria do Estado Moderno construído sobre o conceito de Estado de Direito e estruturado sobre os princípios da legalidade e da separação de poderes ${ }^{11}$. Da mesma forma, Hely Lopes Meirelles afirma que o impulso decisivo para a formação da matéria foi dado pela teoria da separação dos poderes desenvolvida por Montesquieu e acolhida universalmente pelo Estado de Direito, que teria rompido com o absolutismo reinante até então, supostamente caracterizado por uma centralização de poderes que não permitia o reconhecimento de direitos aos súditos ${ }^{12}$.

\footnotetext{
${ }^{8}$ DALLARI, Dalmo de Abreu. Elementos de Teoria Geral do Estado. 2016. 33. ed. São Paulo: Saraiva, 2016, p. 144.

9 BINEMBOJM, Gustavo. Uma teoria do direito administrativo: direitos fundamentais, democracia e constitucionalização. 2.ed. rev. e atual. Rio de Janeiro: Renovar, 2008, p. 9.

${ }^{10}$ GROSSI, Paolo. Mitologias Jurídicas da Modernidade (trad.: Arno Dal Ri Júnior). $2^{\mathrm{a}}$ ed. Florianópolis: Boiteux. 2007, p. 14.

11 DI PIETRO, Maria Sylvia Zanella. Direito Administrativo. 27 ed. São Paulo: Atlas, 2014, p. 3.

12 MEIRELLES, Hely Lopes. Direito Administrativo Brasileiro. 42. ed. São Paulo: Malheiros, 2016, p. 54-55.
} 
A explicação também é adotada por Celso Antônio Bandeira de Mello, para quem a Revolução Francesa tornou necessária a criação de disposições que subjugassem ao direito a conduta soberana do Estado em suas relações com os administrados, inexistentes no período histórico precedente da Monarquia Absoluta ${ }^{13}$. Em sentido muito semelhante Odete Medauar afirma categoricamente que o Direito Administrativo começou a se formar nas primeiras décadas do século XIX, quando as concepções político-institucionais propiciaram o surgimento de normas limitadoras do exercício dos poderes estatais ${ }^{14}$.

E, por fim, é da mesma forma que Rafael Carvalho Rezende Oliveira descreve o nascimento do direito administrativo, visto como resultado da consagração dos ideais da Revolução Francesa, com a consequente limitação do poder estatal e proteção dos cidadãos pelos princípios da legalidade e da separação de poderes, e pela consagração dos direitos fundamentais na Declaração dos Direitos do Homem e do Cidadão. ${ }^{15}$

Diante desse panorama faz-se necessária uma revisão crítica da mitologia que se encontra nas bases do direito administrativo contemporâneo. Como explica Paolo Grossi, é mesmo esse o papel do historiador do direito: o de servir como "consciência crítica" do operador do direito positivo, revelando a complexidade do que pode parecer simples, rompendo convicções acríticas, relativizando certezas absolutas e insinuando dúvidas sobre lugares comuns recebidos sem adequada confirmação cultural. ${ }^{16}$

Seguindo as suas recomendações, este trabalho pretende contribuir para liberar a gênese do Estado e do direito administrativo do lugar comum representado pelo conceito de interesse público, exercitando sobre este objeto uma compreensão autenticamente historiográfica e, consequentemente, crítica. Uma compreensão desse tipo pode colaborar para uma avaliação mais precisa do papel desempenhado pelo conceito no processo histórico de construção de um discurso legitimador da atividade de governo do Estado Moderno.

Afinal, desde a sua invenção as práticas de governamentalidade do Estado Moderno se fundam sobre uma racionalidade de busca pelo bem comum, conceito cuja insegurança e

\footnotetext{
${ }^{13}$ MELLO, Celso Antônio Bandeira de. Curso de Direito Administrativo. 27. ed. rev. e atual. São Paulo: Malheiros, 2010, p. 39.

14 MEDAUAR, Odete. Direito Administrativo Moderno. 8. ed. rev. e atual. São Paulo: Revista dos Tribunais, 2004, p. 34-35.

15 OLIVEIRA, Rafael Carvalho Rezende. Curso de Direito Administrativo. 5. ed. rev., atual. e ampl. São Paulo: Forense, 2017, p. 71.

${ }^{16}$ GROSSI, Paolo. Mitologias Jurídicas da Modernidade (trad.: Arno Dal Ri Júnior). $2^{\mathrm{a}}$ ed. Florianópolis: Boiteux. 2007, p. 13.
} 
instabilidade são incessantemente instrumentalizadas num discurso de legitimação das intervenções governamentais do Estado sobre a vida dos indivíduos e populações.

Para isso é necessário, em primeiro lugar, identificar as limitações e equívocos da estrutura padrão de raciocínio sobre a história do Estado e do surgimento do direito administrativo, e, o pecado original dessa narrativa se encontra no método de construção de seu mito fundacional. É que a história do direito não pode ser compreendida como encadeamento sequencial evolutivo de fatos inevitavelmente fadados ao sucesso.

Uma abordagem histórica do direito administrativo, ciente de seu papel e de suas limitações, não pode jamais esquecer que o deslocamento temporal, além de ser a principal ferramenta do historiador, é também o seu maior desafio. Por um lado, enxergar o passado com os olhos do presente é incorrer em anacronismo, que nos impede de compreender o passado e nos leva a submetê-lo aos pontos de vista do presente. Por outro, retirar o sujeito de seu tempo histórico pela aniquilação de sua subjetividade é utopia irrealizável, a não ser aos olhos do mesmo historiador anacrônico que se ilude ao acreditar enxergar, com as lentes sincrônicas que lhe fornece o presente, a realidade diacrônica do passado histórico.

De fato, a operação intelectual que permite apreender um momento histórico, ou a decisão volitiva que permite eleger um elemento do real como histórico, envolvem dificuldades mais complexas do que parecem enxergar os manuais da dogmática jurídica, e cuja compreensão é imprescindível para evitarmos a transposição meta-histórica de conceitos jurídicos que apenas existem em contextos empíricos particulares.

Como demonstra Ricardo Marcelo Fonseca ${ }^{17}$, o encadeamento linear de fatos históricos acaba promovendo a exclusão de quaisquer elementos cujo significado não seja imediatamente apreensível para a cultura de chegada, e a manutenção somente dos elementos facilmente identificáveis. Esse filtro inconsciente gera uma grave deformação do contexto histórico analisado, que dá origem a uma falsa sensação de familiaridade e identidade entre passado e presente.

O resultado é a concepção de um direito absoluto e permanente, sobrepairando através dos tempos em estado de constância e imobilidade, ou de lenta e contínua evolução até a chegada ao direito contemporâneo, percebido como absoluto, imóvel e inevitável. No mesmo sentido Michel Foucault esclarece que a história organizada como grande sequência de

${ }^{17}$ FONSECA, Ricardo Marcelo. Introdução teórica à história do direito. $1^{\text {a }}$ ed. $3^{\mathrm{a}}$ reimpr. Curitiba: Juruá, 2012, p. 60-61. 
acontecimentos hierarquizados prende o indivíduo no interior de uma totalidade que o ultrapassa e da qual não tem consciência.

A situação exige, então, romper com essa totalidade e com a narrativa do único oficial, de modo a criar espaços de abertura que permitam enxergar com mais clareza, no presente, o regime de diferenças existente nas sociedades do passado ${ }^{18}$. Essa concepção se aproxima do procedimento que Walter Benjamin denomina "escovar a história a contrapelo". Trata-se de promover no presente uma ruptura com os discursos de totalidade do passado, de modo que consigamos vislumbrar as suas características para além da narrativa oficial dos vencedores, nadando contra a corrente da versão oficial da história e possibilitando a recusa ao acompanhamento do cortejo triunfal da história linear. ${ }^{19}$

Desse modo, pretendemos no presente artigo empregar o método arqueogenealógico proposto por Michel Foucault para compreendermos com mais clareza o processo histórico de edificação de um novo modelo de governamentalidade na aurora da modernidade, e o papel atribuído ao relé do "interesse público" nesse novo dispositivo político. Superando as causalidades lineares e as subjetivações abstratas típicas das "concepções econômicas do poder"20, liberais e marxistas, avaliaremos as práticas concretas que culminaram na formação do moderno Estado Administrativo, e as funções desempenhadas pelo direito na estruturação e na legitimação da governamentalidade disciplinar e biopolítica que o definem.

Para isso, iniciaremos por uma apresentação do processo de construção de interesse público na formação da sociedade disciplinar, e de sua instrumentalização por uma governamentalidade ativa que precisa violar direitos preexistentes para instituir uma nova ordem social. Em seguida avaliaremos a sua ressignificação pela sociedade biopolítica, que o vincula a uma racionalidade econômica extrajurídica, e consequentemente extrademocrática, para desenvolver novas formas de intervenção sobre as vidas de indivíduos e coletividades. $\mathrm{E}$, ao final sustentaremos a necessidade de superação do mito fundador do interesse público para que possamos enxergá-lo em sua realidade, como ponto de acúmulo das relações de força existentes na sociedade contemporânea.

\footnotetext{
${ }^{18}$ BURMESTER, Ana Maria de Oliveira. Foucault e o Império. In: RAGO, Margareth; VEIGA-NETO, Alfredo. Figuras de Foucault. 2. ed. Belo Horizonte: Autentica, 2008, p. 40.

19 LÖWY, Michael. Walter Benjamin aviso de incêndio. São Paulo: Boitempo, 2005, p. 73-74.

${ }^{20}$ FOUCAULT, Michel. Em Defesa da Sociedade (trad. Maria Ermantina Galvão). São Paulo: Martins Fontes, 2005, p. 19.
} 


\section{A CONSTRUÇÃO DO INTERESSE PÚBLICO NA SOCIEDADE DISCIPLINAR E A INDETERMINAÇÃO DO INTERESSE PÚBLICO NA SOCIEDADE BIOPOLÍTICA}

A crítica da origem milagrosa do direito administrativo pela limitação heroica dos poderes absolutos de um déspota semidivino encontra suporte teórico valioso no pensamento de Michel Foucault, que permite uma considerável revisão dos sentidos originalmente atribuídos ao conceito fundamental de interesse público. Mas o recurso ao seu pensamento exige ressalvar, primeiramente, que o tipo de abordagem proposto pelo autor para a compreensão das práticas de poder do Estado Moderno em nada se assemelha a uma Teoria de Estado. Aliás, Foucault se negou expressamente a fazê-lo, "assim como podemos e devemos renunciar a um almoço indigesto"21. Deixando de lado a figura abstrata de um Estado onicompreensivo, o pensador francês se concentrou em avaliar as relações particulares existentes entre o exercício concreto de práticas de poder e os processos de constituição de subjetividades. Em suas palavras:

[...] o que eu tentei percorrer, desde 1970-1971, era o 'como' do poder. Estudar o 'como do poder', isto é, tentar apreender seus mecanismos entre dois pontos de referência ou dois limites: de um lado, as regras de direito que delimitam formalmente o poder, de outro lado, a outra extremidade, o outro limite, seriam os efeitos de verdade que esse poder produz, que esse poder conduz e que, por sua vez, reconduzem esse poder. Portanto, triângulo: poder, direito, verdade. ${ }^{22}$

Não obstante, ainda que não tenha desenvolvido uma Teoria do Estado propriamente dita, ao se debruçar sobre o funcionamento das práticas de poder nas sociedades ocidentais modernas Foucault acaba por tratar também do Estado, não mais como ponto de origem e detentor central do poder existente em uma sociedade, mas como apenas mais um dos múltiplos resultados do complexo emaranhado de forças contraditórias que constituem o dispositivo político de uma sociedade determinada. Afinal, para Foucault o poder não é um objeto de estudo "maciço e homogêneo", mas algo que circula, que só funciona em cadeia e jamais está localizado nas mãos de alguns; o poder não é uma coisa, mas uma prática que se exerce em rede, no interior da qual todos se encontram simultaneamente em posição de exercê-lo ou sofrê-

21 FOUCAULT, Michel. Nascimento da Biopolítica (trad. Eduardo Brandão). São Paulo: Martins Fontes, 2008, p. 105.

22 FOUCAULT, Michel. Em Defesa da Sociedade (trad. Maria Ermantina Galvão). São Paulo: Martins Fontes, 2005, p. 28 
lo, de modo que os indivíduos concretos são concebidos como nexos de passagem e intermediários, não como detentores ou espoliados. ${ }^{23}$

Ao seguir essa orientação metodológica o autor se torna capaz de perceber uma transformação fundamental no dispositivo de poder vigente no Ocidente, na passagem do medievo para a modernidade. Segundo o filósofo, enquanto durou a sociedade de tipo feudal, o modo como o poder se exercia coincidia com os termos da relação soberano/súdito, o que fazia com que a teoria da soberania descrevesse adequadamente a mecânica geral de poder na sociedade, desde os seus níveis mais elevados até os seus níveis mais baixos ${ }^{24}$. Ocorre que na passagem para o século XVIII a explosão demográfica e industrial da sociedade europeia fez com que esse dispositivo de poder soberano não fosse mais suficientemente adequado ao desempenho de suas funções, sendo paulatinamente substituído por um novo mecanismo de controle social. $O$ investimento industrial da riqueza em uma materialidade não-monetária (mercadorias, estoques, máquinas, oficinas, matérias-primas, etc.) deixou-a diretamente exposta ao roubo e à depredação, o que não ocorria quando a riqueza existente era investida predominantemente em terras e moeda. A consequente transformação do padrão de ilegalismos, da sonegação para o furto e destruição, aliada ao risco gerado pelo inevitável contato direto da população mais pobre com a riqueza disponível (na medida em que o modelo exige a sua incorporação como força de trabalho), passaram a exigir um novo mecanismo de poder que fosse capaz de proteger a sua nova forma material. ${ }^{25}$

Essa nova mecânica de poder era absolutamente incompatível com a relação de soberania típica da sociedade feudal, pois se tratava de um poder que era "mais uma trama cerrada de coerções materiais do que a existência física de um soberano" ${ }^{26}$. A reterritorialização das práticas disciplinares que vinham sendo construídas pela pastoral católica desde o Alto Medievo em uma nova tecnologia laica tornou possível o surgimento de um novo dispositivo de poder. Nascem então as disciplinas, práticas que se prestam a docilizar o sujeito, reduzir sua força política e maximizar sua força econômica, de modo a permitir que seja seguramente

${ }^{23}$ FOUCAULT, Michel. Em defesa da sociedade (trad. Maria Ermantina Galvão). São Paulo: Martins Fontes, 2005, p. 34-35.

${ }^{24}$ FOUCAULT, Michel. Em defesa da sociedade (trad. Maria Ermantina Galvão). São Paulo: Martins Fontes, 2005, p. 40-41.

${ }^{25}$ FOUCAULT, Michel. A Verdade e as Formas Jurídicas (trad. Roberto Cabral de Melo Machado e Eduardo Jardim Morais). Rio de Janeiro: Nau, 2002, p. 100-101.

${ }^{26}$ FOUCAULT, Michel. Em defesa da sociedade (trad. Maria Ermantina Galvão). São Paulo: Martins Fontes, 2005, p. 42. 
colocada em suas mãos a nova materialidade das riquezas da sociedade capitalista ${ }^{27}$. Vale mencionar, por sua clareza, a explicação de Roberto Machado:

Foi esse tipo específico de poder que Foucault chamou de "disciplina" ou "poder disciplinar". É importante notar que a disciplina nem é um aparelho de Estado, nem uma instituição: ela funciona como uma rede que os atravessa sem se limitar a suas fronteiras; é uma técnica, um dispositivo, um mecanismo, um instrumento de poder; são "métodos que permitem o controle minucioso das operações do corpo, que asseguram a sujeição constante de suas forças e thes impõem uma relação de docilidade-utilidade"; é o diagrama de um poder que não atua do exterior, mas trabalha o corpo dos homens, manipula seus elementos, produz seu comportamento, enfim, fabrica o tipo de homem necessário ao funcionamento e manutenção da sociedade industrial, capitalista. Ligada à explosão demográfica do século XVIII e ao crescimento do aparelho de produção, a dominação política do corpo que ela realiza responde à necessidade de sua utilização racional, intensa, máxima, em termos econômicos. Mas, por outro lado - e isso é um aspecto bastante importante da análise -, o corpo só se torna força de trabalho quando trabalhado pelo sistema político de dominação característico do poder disciplinar. ${ }^{28}$

A formação da nova tecnologia de poder transforma também as práticas de governamentalidade estatal, que deixam de atuar sob o modelo de soberania para absorverem as práticas disciplinares desenvolvidas na periferia do sistema político. Desenvolve-se a nova razão de Estado, que o situa na posição privilegiada de governante dos homens e das populações, atribuindo-lhe o novo objetivo de domesticação de subjetividades. 0 resultado é a passagem de um Estado Jurisdicional, que tinha no soberano apenas o magistrado competente para dizer o direito e impor eventual sanção ao súdito (de preferência pela via do espetáculo), para um Estado que se mostra personagem ativo na constituição da ordem social, que busca disciplinar seus administrados, adestrá-los e torná-los mais úteis ao fortalecimento e à defesa da sociedade. E entre os diversos instrumentos empregados por esse novo Estado Disciplinar na realização de suas tarefas se encontra também a nova ciência do direito administrativo, parte específica do Direito que se destina a demonstrar não só a existência do Poder Público como personagem autônomo, mas também a sua independência em relação ao Poder Judiciário. 0 antigo Estado que "mantinha" as coisas se transforma em um Estado que "faz" coisas. Que disciplina os corpos, governa os homens e mantém organizada a sociedade, e ao qual,

27 GUANDALINI JUNIOR, Walter. A crise da sociedade de normalização e a disputa jurídica pelo biopoder: o licenciamento compulsório de patentes de antirretrovirais. Curitiba. 2006. 213f. Dissertação (Mestrado) - Programa de Pós-Graduação em Direito, Universidade Federal do Paraná, p. 16-17.

${ }^{28}$ MACHADO, Roberto. Foucault, a ciência e o saber. 3. ed. rev. e ampl. Rio de Janeiro: Zahar, 2006, p. 124. 
naturalmente, se atribui o poder necessário para que o faça ${ }^{29}$, o poder "administrativo", cujo exercício passa a estar intimamente ligado ao conceito jurídico fundamental do "interesse público".

Uma noção mais abstrata de interesse pertencente à própria comunidade, concebido de forma dissociada dos interesses de seus integrantes, começa a se formar primeiramente no curso do século XVIII, quando as necessidades do contexto de competição econômica e militar internacional passam a exigir das monarquias europeias o desenvolvimento de práticas de governo qualitativamente distintas da iurisdictio medieval. Ocorre então um crescimento progressivo do poder regulatório do centro político, que passa a se projetar ativamente em direção à periferia através da polícia, atividade responsável pela garantia da segurança, harmonia e bem-estar da comunidade, e que se manifesta por meio de uma intervenção ativa de governo sobre a vida dos indivíduos e grupos sociais.

Essa ação se distingue claramente da ação jurisdicional típica das sociedades do antigo regime, na medida em que se afirma como manifestação do poder de criação de uma nova ordem por parte dos governantes. Trata-se de uma profunda alteração do modo como se compreendem as responsabilidades e tarefas atribuídas ao soberano, não mais concebido como protetor dos direitos e privilégios tradicionais, mas como criador de novos direitos e obrigações o que o torna, inevitavelmente, violador dos direitos e privilégios tradicionais que até então the incumbia proteger. Nessas circunstâncias a noção de "interesse público", "geral” ou "coletivo" se torna um suporte fundamental para o novo modelo de ação governamental, na medida em que justifica a ação disruptiva do soberano como sendo realizada não em benefício de si mesmo ou de grupos sociais privilegiados, mas no interesse de toda a comunidade. Graças a essa nova concepção o trabalho de criação de uma nova ordem pode se travestir de restauração da ordem original, agora em novos termos, mais justos e equilibrados para todos os integrantes da sociedade.

A afirmação completa do interesse público como fundamento da ação de governo é realizada com a superação definitiva do Estado de Justiça pela Revolução Francesa de 1789. A destruição dos corpos intermediários entre o soberano e a nação permite que o Estado assuma a integralidade das tarefas até então atribuídas às autoadministrações inferiores, e a nova lógica democrática de organização da vida política torna mais clara a vinculação entre as ações de governo e os interesses da coletividade, agora identificada com a integralidade da Nação, não

${ }^{29}$ GUANDALINI JUNIOR, Walter. História do direito administrativo brasileiro: formação (1821-1895). Curitiba: Juruá, 2016, p. 131. 
mais com corporações e grupos parciais. O Estado abandona completamente a sua atividade de árbitro e assume irrestritamente a sua nova vocação de criador ativo da ordem social. Com isso recebe amplas prerrogativas de império para a constituição e execução de novas regras administrativas, restringindo os direitos preexistentes em benefício da instituição de um novo modelo de convívio urbano.

Como se vê, a compreensão do processo de constituição do direito administrativo no contexto específico de formação da sociedade disciplinar não só põe em crise o mito da subjugação do império do Estado ao poder da Lei ${ }^{30}$. Mas também subverte a ordem préestabelecida da narrativa pós-revolucionária, normalmente contada como um momento de Estado ausente, cujo único propósito seria servir de aparato para que, através de um bom e organizado meio social, o indivíduo pudesse exercer, com plenitude, todas as liberdades garantidas pela lei. Vitória da burguesia, vitória do direito, vitória dos vencedores. E, como ressalta Walter Benjamin, em sua Tese VII sobre o conceito de história:

[...] Todo aquele que, até hoje, obteve a vitória, marcha junto no cortejo de triunfo que conduz os dominantes de hoje (a marcharem) por cima dos que, hoje, jazem por terra. A presa, como de costume, é conduzida ao cortejo triunfante. Chamam-na bens culturais. [...] Nunca há um documento da cultura que não seja, ao mesmo tempo, um documento da barbárie. $[. . .]^{31}$.

Mas a drástica crítica benjaminiana não deve obscurecer o importante papel desempenhado pelo direito no arranjo da nova ordem política. 0 novo dispositivo continua dependente do direito, não somente como elemento de mascaramento das técnicas de dominação sempre presentes nas práticas disciplinares (atuando negativamente, como “ideologia”). Mas principalmente como elemento de resistência da nova correlação de forças aos esforços de restauração, sempre contidos pelo argumento democrático tornado possível pelo modelo de soberania popular (atuando positivamente, como ferramenta de construção). Nas palavras de Michel Foucault:

Ora, de fato, a teoria da soberania não só continuou a existir, se vocês quiserem, como ideologia do direito, mas também continuou a organizar os códigos jurídicos que a Europa do século XIX elaborou para si a partir dos códigos napoleônicos. Por que a teoria da soberania persistiu assim como ideologia e como princípio organizador dos grandes códigos jurídicos? Eu creio que há para isso duas razões. De um lado, a teoria da soberania foi, no século XVIII e ainda no século XIX, um instrumento crítico permanente contra a monarquia e contra

30 Verificável, por todos, na obra clássica de MELLO, Celso Antônio Bandeira de. Curso de Direito Administrativo. 27. ed. rev. e atual. São Paulo: Malheiros, 2010, p. 47.

31 LÖWY, Michael. Walter Benjamin aviso de incêndio. São Paulo: Boitempo, 2005, p. 70. 
todos os obstáculos que podiam opor-se ao desenvolvimento da sociedade disciplinar. Mas, de outro, essa teoria e a organização de um código jurídico, centrado nela, permitiram sobrepor aos mecanismos da disciplina um sistema de direito que mascarava os procedimentos dela, que apagava o que podia haver de dominação e de técnicas de dominação na disciplina e, enfim, que garantia a cada qual que ele exercia, através da soberania do Estado, seus próprios direitos soberanos. Em outras palavras, os sistemas jurídicos, sejam as teorias, sejam os códigos, permitiram uma democratização da soberania, a implantação de um direito público articulado a partir da soberania coletiva, no mesmo momento, na medida em que e porque essa democratização da soberania se encontrava lastrada em profundidade pelos mecanismos da coerção disciplinar. De uma forma mais densa, poderíamos dizer o seguinte: uma vez que as coerções disciplinares deviam ao mesmo tempo exercer-se como mecanismos de dominação e ser escondidas como exercício efetivo do poder, era preciso que fosse apresentada no aparelho jurídico e reativada, concluída, pelos códigos judiciários, a teoria da soberania. ${ }^{32}$

A edificação das novas práticas de governo e a invenção de um novo campo de saber que as orientasse e corroborasse não foram suficientes para dispensar um direito próprio que as regulasse. E foi justamente o nascente direito público, articulado em torno das noções de soberania coletiva e democracia, o responsável pela criação do novo conceito-ideal de “interesse público", efeito de verdade a partir do qual a ordem jurídica passou a se apresentar como capaz de controlar os atos da administração que interferissem de forma abusiva nos direitos individuais, legitimando a própria ação interventiva com a imagem de uma autoridade soberana finalmente democratizada e popular. Não é, em suma, a unidade do objeto busca pelo interesse público como finalidade estatal que constitui a unidade de estudo do direito público. Mas, ao contrário, a noção de "interesse público" que é constituída como finalidade das novas práticas de governo estatal por efeito de tudo o que se disse a seu respeito ${ }^{33}$.

O discurso do interesse público é manejado como instrumento de organização e mascaramento dos mecanismos disciplinares no interior do aparato estatal, não apenas legitimando ideologicamente, mas principalmente articulando juridicamente as próprias disciplinas com os relés teórico-políticos da democracia e da soberania popular, o que promove uma multiplicação exponencial do seu poder de intervenção ${ }^{34}$. Mas para isso o direito

32 FOUCAULT, Michel. Em Defesa da Sociedade (trad. Maria Ermantina Galvão). São Paulo: Martins Fontes, 2005, p. 44.

${ }^{33}$ A expressão é paráfrase de Roberto Machado, que utiliza a mesma construção para se referir à loucura como criação da psicopatologia em MACHADO, Roberto. Foucault, a ciência e o saber. 3. ed. rev. e ampl. Rio de Janeiro: Zahar, 2006, p. 104.

34 É claro que o interesse público está sempre articulado com outros conceitos, como os de "mérito" e "discricionariedade" administrativa, ou "conveniência" e "oportunidade". É que esses conceitos possuem as mesmas regras no campo pré-conceitual, relacionadas ao fazer intermitente estatal que, na busca pelo bem de todos, age de forma discricionária, possuidor de uma margem de "conveniência" e "oportunidade" 
administrativo não poderia agir sozinho, era obrigado a se conectar a um complexo normativo embrionário, por intermédio do qual pudesse se expandir para contaminar os vários ramos da ordem jurídica. E foi justamente o que fez ao se associar ao discurso do constitucionalismo. Graças a essa articulação a narrativa clássica pôde apresentar o direito administrativo como regulação jurídica do poder estatal, permitindo a instauração do Estado de Direito pela imposição de amarras que eliminassem a arbitrariedade de toda ação estatal. Nas exatas palavras de Luís Roberto Barroso ${ }^{35}$ :

A Constituição, portanto, cria ou reconstrói o Estado, organizando e limitando o poder político, dispondo acerca de direitos fundamentais, valores e fins públicos e disciplinando o modo de produção e os limites de conteúdo das normas que integrarão a ordem jurídica por ela instituída. Como regra geral, terá a forma de um documento escrito e sistemático, cabendo-lhe o papel, decisivo no mundo moderno, de transportar o fenômeno político para o mundo jurídico, convertendo o poder em Direito.

Nada mais legítimo e forte do que a própria ideia da Constituição para solucionar o impasse, ao mesmo tempo em que cria a ideia de contenção do Estado ${ }^{36}$ nas amarras jurídicas do direito administrativo, assegura o caráter legítimo e democrático do exercício do seu poder, ao apresentá-lo como fera enjaulada destinada a um propósito específico, resguardar o bem comum e proteger as liberdades dos indivíduos. Assim se apresenta uma concepção de Estado autocontido e imóvel, que se permite intervir somente naqueles casos em que é o próprio interesse público a exigi-lo. Mas o interesse público sempre exige.

Durante a existência da sociedade disciplinar a razão de Estado que orientava as intervenções administrativas na vida social era limitada externamente e ilimitada internamente, se por um lado o dispositivo diplomático-militar fazia com que os Estados se encontrassem em uma relação de concorrência limitada entre iguais. Por outro lado o dispositivo de polícia absorvido pelo direito administrativo tinha o objetivo explícito de fazer com que, internamente, as forças do Estado crescessem o máximo possível, inclusive como condição de possibilidade da concorrência no âmbito externo. Nesse contexto, a única forma de limitação à manifestação interna da razão de Estado era representada pelo próprio direito público (constitucional e

que o Poder Judiciário não pode adentrar, salvo para controlar a legitimidade e legalidade dos atos da administração.

35 BARROSO, Luís Roberto. Curso de Direito Constitucional Contemporâneo: os conceitos fundamentais e a construção do novo modelo. São Paulo: Saraiva, 2009, p. 74-75, grifo nosso.

36 "Constitucionalismo significa, em essência, limitação do poder e supremacia da lei (Estado de direito, rule of law, Rechtstaat)", segundo BARROSO, Luís Roberto. Curso de Direito Constitucional Contemporâneo: os conceitos fundamentais e a construção do novo modelo. São Paulo: Saraiva, 2009, p. 87-88. 
administrativo), que conduzia as atividades interventivas pelas calhas estreitas, mas abertas, do atendimento ao interesse público e da proteção das liberdades individuais.

A partir do século XVIII a razão de Estado passa a sofrer severas críticas, a partir das quais a forma de governamentalidade representada pela razão de Estado passou a receber um novo conteúdo. O desenvolvimento da economia política constrói uma ciência da eficácia dos atos de governo, sobre a base da qual se torna possível vislumbrar um campo de naturalidade próprio da ação governamental, que deve obrigatoriamente ser respeitado pelo Estado sob pena de os seus atos tornarem-se incapazes de atingir os objetivos pretendidos. O raciocínio dá origem a uma nova forma de contenção dos atos de governo, agora exercida do interior da própria governamentalidade. Isso faz com que a autolimitação instituída deixe de ser uma limitação de direito e se transforme em uma limitação de fato, não mais fundada em critérios de legitimidade e respeito à liberdade individual, mas somente de eficácia e conveniência. A divisão entre o que se deve fazer e o que não convém fazer não ocorre mais por uma clivagem nos sujeitos, com o estabelecimento formal de um campo de liberdade e outro de obediência; as prescrições de conduta para o governante se estabelecem no próprio domínio da prática governamental, em relação à sua naturalidade específica ${ }^{37}$. Nas palavras de Foucault, a partir do século XVIII o que se opõe ao detentor do poder não é mais o abuso (ilegítimo) da soberania, mas o excesso (em desacordo com a realidade) de governo ${ }^{38}$.

O estabelecimento de um princípio de autolimitação do governo a partir da naturalidade econômica dos seus objetos é o ponto de partida para a organização de uma biopolítica, na medida em que a as intervenções de governo deixam de se apresentar como limitação dos comportamentos dos indivíduos e passam a se apresentar como gestão dos movimentos naturais das populações. Assim se formam as sociedades de segurança, cujo dispositivo biopolítico trata um determinado fenômeno em sua naturalidade no interior de uma série de eventos prováveis, inserindo as reações do poder em um cálculo de intervenção sobre o meio, com o objetivo de regular a gestão da vida das populações, sua saúde, higiene, alimentação, sexualidade, natalidade. Atua, então, sobre a base de informações estatísticas extraídas da realidade para o estabelecimento de curvas de normalidade, com base nas quais desenvolve um controle político que permite a gestão dos movimentos populacionais sem violação de sua própria naturalidade ${ }^{39}$.

37 GUANDALINI JUNIOR, Walter. Doença, Poder e Direito. Curitiba: Juruá. 2010, p. 35.

38 FOUCAULT, Michel. Nascimento da Biopolítica (trad. Eduardo Brandão). São Paulo: Martins Fontes, 2008, p. 14.

39 REVEL, Judith. Michel Foucault: conceitos essenciais. São Carlos: Claraluz, 2005, p. 26. 
Mas a substituição do princípio de autolimitação jurídica por um princípio de autolimitação econômica não libera o dispositivo biopolítico da necessidade de recorrer ao direito para se organizar. É que a ordem jurídico-discursiva que orienta a intervenção estatal à proteção do interesse público continua presente, agora não apenas para mascarar as disciplinas e legitimar a atuação estatal, mas também para estruturar a intervenção do Estado nos corpos biológicos das populações. A nova governamentalidade biopolítica permanece dependente de uma atuação administrativa desenvolvida sob o signo do direito público, que regula a ação estatal e a direciona à realização do interesse público. Mas o processo de construção desse novo interesse público é completamente subtraído à competência própria do direito vigente, que se limita a reconhecer a "conveniência" e "oportunidade" de decisões de eficácia tomadas por uma racionalidade econômica extrajurídica,e, extrademocrática, e extrapopular.

Antes estruturado para mascarar as disciplinas, o conceito de interesse público se apresentava simultaneamente como elemento legitimador e amarra de contenção, com a formação do dispositivo biopolítico das sociedades de segurança o conceito se torna ainda mais incerto e perigoso. Pois o critério de sua definição deixa de ser pautado por uma concepção de soberania democrática e popular fundada nas vontades dos cidadãos para ser construído de modo tecnocrático por um conjunto de especialistas fundados em um saber especializado e inacessível ao cidadão comum. E as intervenções administrativas da nova governamentalidade biopolítica não incidem somente sobre os comportamentos dos indivíduos, mas sobre os movimentos biológicos dos grupos populacionais. É o que ocorre, por exemplo, quando o Estado se ocupa da gestão da saúde de grupos sociais, promovendo campanhas de vacinação para uma determinada faixa etária, ou autorizando (ou proibindo) a distribuição de remédios e tratamentos para determinados setores da sociedade. Noutras palavras, através do discurso da supremacia do interesse público (e também das conveniências, oportunidades e discricionariedades da administração) o agir estatal da sociedade de segurança cria a necessidade de agora intervir diretamente na vida da população. Decidindo se faz viver mais tempo, quando autoriza um tratamento, ou se deixa morrer antecipadamente, quando proíbe a circulação de determinado medicamento, por exemplo.

E o direito administrativo é um campo fértil para a atuação interventiva do biopoder: decretos regulamentares, instruções normativas de agências reguladoras, licenças e autorizações de polícia, campanhas de vacinação, distribuição gratuita de certos medicamentos ou tratamentos através do SUS. E, mais recentemente, internações compulsórias de dependentes químicos, tudo é materializado em atos e procedimentos administrativos, praticados com o 
objetivo de preservar o “interesse público" definido por especialistas e permeado pelos conceitos nebulosos de discricionariedade, conveniência, oportunidade, mérito administrativo. Por meio desses instrumentos permanece realizando, em nome do interesse público, o governo dos indivíduos e das populações, fazendo-os viver ou deixando-os morrer para a defesa da sociedade.

\section{CONCLUSÃO}

O presente estudo examinou o papel desempenhado pelo conceito de interesse público no contexto da sociedade disciplinar e biopolítica. Buscando compreender de uma perspectiva crítica esse que é um dos mitos fundadores do moderno Estado Administrativo (e do direito que o regula), esforçamo-nos para demonstrar que o Estado criado pela Revolução Francesa não é um Estado "contido pelo direito" como deseja a dogmática clássica, mas um Estado criado para fazer coisas e governar indivíduos e populações. Este "fazer estatal" se pauta num discurso cuja racionalidade pretende atribuir-lhe a finalidade específica de proteção do interesse público, mas que veicula práticas disciplinares e biopolíticas cuja existência é tradicionalmente ignorada pelo saber jurídico.

Esclarecer a função política (disciplinar e biopolítica) desempenhada nesse contexto pelo conceito jurídico de interesse público exigiu demonstrar a sua conexão teórica com as bases do constitucionalismo moderno e a sua vinculação fática às práticas de governamentalidade do Estado contemporâneo. A observação desses pontos de contato permitiu compreender o importante papel desempenhado pelo direito administrativo como correia de transmissão de práticas disciplinares e biopolíticas, sob a aparência de instrumento de contenção do Estado para a preservação das liberdades dos indivíduos.

A análise genealógica do modo como se constituiu e desenvolveu historicamente o conceito jurídico de interesse público tornou possível a crítica do mito fundador, e a consequente superação das concepções estáticas, absolutas e transcendentais da dogmática jurídica clássica em prol de uma relativização mobilizadora das certezas subservientemente aceitas pela moderna teoria do direito administrativo. Assim pôde-se repensar as bases da episteme de nossa época jus-administrativa, compreendendo-se os conceitos de interesse público, mérito administrativo, conveniência e oportunidade como elementos discursivos cujas 
racionalidades encontram um denominador comum no campo pré-conceitual, composto pelas relações de força instituídas pelo dispositivo político da sociedade disciplinar e da sociedade de segurança.

\section{REFERÊNCIAS}

BARROS, André D’Assunção. Teoria da História Vol. III: Os paradigmas revolucionários. Rio de Janeiro: Vozes, 2011.

BARROSO, Luís Roberto. Curso de Direito Constitucional Contemporâneo: os conceitos fundamentais e a construção do novo modelo. São Paulo: Saraiva, 2009.

BINEMBOJM, Gustavo. Uma teoria do direito administrativo: direitos fundamentais, democracia e constitucionalização. 2.ed. rev. e atual. Rio de Janeiro: Renovar, 2008.

BIROLLI, Flavia. História, discurso e poder em Michel Foucault. In: RAGO, Margareth; VEIGANETO, Alfredo. Figuras de Foucault. 2. ed. Belo Horizonte: Autentica, 2008

BURMESTER, Ana Maria de Oliveira. Foucault e o Império. In: RAGO, Margareth; VEIGA-NETO, Alfredo. Figuras de Foucault. 2. ed. Belo Horizonte: Autentica, 2008.

CARVALHO FILHO, José dos Santos. Manual de Direito Administrativo. 28. ed. rev., ampl. e atual. São Paulo: Atlas, 2015.

DALLARI, Dalmo de Abreu. Elementos de Teoria Geral do Estado. 2016. 33. ed. São Paulo: Saraiva, 2016.

DI PIETRO, Maria Sylvia Zanella. Direito Administrativo. 27 ed. São Paulo: Atlas, 2014.

DUARTE, André. Biopolítica e resistência: o legado de Michel Foucault. In: RAGO, Margareth. VEIGA-NETO, Alfredo. Figuras de Foucault. 2. ed. Belo Horizonte: Autentica, 2008.

FONSECA, Ricardo Marcelo. Introdução teórica à História do Direito. 1. ed. 2. reimpr. Curitiba: Juruá, 2011.

FOUCAULT, Michel. A Ordem do Discurso (trad. Laura Fraga de Almeida Sampaio). $7^{a}$ ed. São Paulo: Loyola, 2001.

FOUCAULT, Michel. A Verdade e as Formas Jurídicas (trad. Roberto Cabral de Melo Machado e Eduardo Jardim Morais). Rio de Janeiro: Nau, 2001.

FOUCAULT, Michel. As Palavras e as Coisas (trad. Salma Tannus Muchail). 8. ed. São Paulo: Martins Fontes, 2000. 
FOUCAULT, Michel. Em Defesa da Sociedade (trad. Maria Ermantina Galvão). São Paulo: Martins Fontes, 2005.

FOUCAULT, Michel. História da Sexualidade vol. 1 - A Vontade de Saber (trad. Maria Thereza da Costa Albuquerque e J. A. Guilhon Albuquerque). Rio de Janeiro: Graal, 1999.

FOUCAULT, Michel. Nascimento da Biopolítica (trad. Eduardo Brandão). São Paulo: Martins Fontes, 2008.

FOUCAULT, Michel. Segurança, território e população: curso dado no College de France (19771978) (trad. Eduardo Brandão). São Paulo: Martins Fontes, 2008.

GROSSI, Paolo. Mitologias Jurídicas da Modernidade (trad.: Arno Dal Ri Júnior). $2^{\mathrm{a}}$ ed.

Florianópolis: Boiteux. 2007.

GUANDALINI JUNIOR, Walter. Doença, Poder e Direito. Curitiba: Juruá. 2010.

GUANDALINI JUNIOR, Walter. História do direito administrativo brasileiro: formação (18211895). Curitiba: Juruá, 2016.

LÖWY, Michael. Walter Benjamin aviso de incêndio. São Paulo: Boitempo, 2005.

MACHADO, Roberto. Foucault, a ciência e o saber. 3. ed. rev. e ampl. Rio de Janeiro: Zahar, 2006.

MASCARO, Alysson Leandro. Filosofia do Direito. 5. ed. rev. atual. e ampl. São Paulo: Atlas, 2016.

MEDAUAR, Odete. Direito Administrativo Moderno. 8. ed. rev. e atual. São Paulo: Revista dos Tribunais, 2004.

MEIRELLES, Hely Lopes. Direito Administrativo Brasileiro. 42. ed. São Paulo: Malheiros, 2016. MELLO, Celso Antônio Bandeira de. Curso de Direito Administrativo. 27. ed. rev, e atual. São Paulo: Malheiros, 2010.

OLIVEIRA, Rafael Carvalho Rezende. Curso de Direito Administrativo. 5. ed. rev., atual. e ampl. São Paulo: Forense, 2017.

RAGO, Margareth. VEIGA-NETO, Alfredo. Figuras de Foucault. 2.ed. Belo Horizonte: Autentica, 2008.

REVEL, Judith. Michel Foucault: conceitos essenciais. São Carlos: Claraluz, 2005. 


\section{COMO FAZER REFERÊNCIA AO ARTIGO (ABNT):}

TEIXEIRA, Livia Solana Pfuetzenreiter de Lima; GUANDALINI JUNIOR, Walter. Mitologias jurídicas do estado administrativo: crítica genealógica da noção de interesse público. Revista Eletrônica do Curso de Direito da UFSM, Santa Maria, RS, v. 14, n. 2, e31598, maio./ago. 2019. ISSN 1981-3694. DOI:

http://dx.doi.org/10.5902/1981369431598. Disponível em:

https://periodicos.ufsm.br/revistadireito/article/view/31598 Acesso em: dia mês. ano.

Direitos autorais 2019 Revista Eletrônica do Curso de Direito da UFSM

Editores responsáveis: Rafael Santos de Oliveira e Angela Araujo da Silveira Espindola

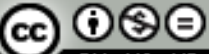

Esta obra está licenciada com uma Licença Creative Commons Atribuição-NãoComercial-SemDerivações 4.0 Internacional.

\section{SOBRE OS AUTORES}

LiVia Solana PfuetzenReIter de Lima Teixeira

Graduada em Direito pela FURB - Fundação Universidade Regional de Blumenau (2009), especialista em Ciências Criminais pela Anhanguera-UNIDERP (2011), e Mestre em Direito no programa público da UNINTER, na linha de pesquisa de Teoria e História da Jurisdição (2019). Atualmente é Professora Substituta de Direito Administrativo e Direito Processual Penal da Fundação Universidade Regional de Blumenau - FURB, lecionando também no cursinho para concursos e OAB "Academia da Aprovação", em Blumenau. Assessora de Gabinete na 5. ${ }^{a}$ Vara Cível da Capital - Tribunal de Justiça do Estado de Santa Catarina

WALTER GUANDALINI JUNIOR

Possui graduação em Direito pela Universidade Federal do Paraná (2003), mestrado em Direito do Estado pela Universidade Federal do Paraná (2006) e doutorado em Direito do Estado pela Universidade Federal do Paraná (2011). Programa de Doutorado com Estágio no Exterior (PDEE - Doutorado-sanduíche) pelo Centro di Studi per la Storia del Pensiero Giuridico Moderno, Università di Firenze (2010). Atualmente é professor adjunto da Faculdade de Direito da Universidade Federal do Paraná e advogado sênior da Companhia Paranaense de Energia. Tem experiência na área de Direito, com ênfase em Direito Público, História do Direito e Direito Romano. 